\title{
Cardiovascular risk factors in women
}

\author{
BY CHRISTINE M. WILLIAMS \\ Hugh Sinclair Unit of Human Nutrition, Department of Food Science and Technology, \\ University of Reading, Reading RG6 6AP
}

Rates of CHD have been shown to be considerably higher in men than women in all countries where reliable prevalence data are available, including those countries with low rates of the disease, such as Japan (World Health Organization, 1989). In the UK, for women at any given age, the death rate for CHD is approximately equivalent to that seen in men 10 years earlier (Fig. 1). This earlier presentation in men means that CHD often occurs during a man's active middle years, with consequently greater social and economic impact on individuals and their families. These differences in age at occurrence have almost certainly contributed to the perception that CHD is a disease of men and one to which women are relatively resistant. Whilst it is certainly true that being female confers some protection against $\mathrm{CHD}$, it is also true that CHD is a major cause of death in women, responsible for $23 \%$ of all female mortality and the major cause of premature death in women less than 60 years old (Office of Population Censuses and Surveys, 1993). It is also well established that women who suffer a myocardial infarct (MI) have a poorer prognosis than men. In the Framingham study, the 12-month mortality after MI was $45 \%$ for women and $20 \%$ for men (Kannel et al. 1979). This could be related to their greater age at occurrence or to the greater prevalence of factors such as diabetes or hypertension in women compared with men. It has also been shown that following an MI, women are less likely to be offered intensive drug and surgical therapy.

Others have suggested that the later occurrence and greater severity at first $\mathrm{MI}$ in women are due to differences in the biological processes involved (Walsh \& Grady, 1995) and, for this reason, the assumption that cardiovascular risk factors are the same in men and women may be incorrect (Hulley et al. 1992). This question is difficult to address because much of the research into the causes, prevention and treatment of the disease has been conducted only in men and provides an inadequate basis for discriminating gender-specific risk factors in CHD.

\section{CARDIOVASCULAR RISK FACTORS}

A large body of research evidence has established age, smoking, hypertension, raised blood cholesterol and obesity as risk factors in CHD (Table 1). More recently, research has concentrated on the role of haemostatic factors (Meade et al. 1986; Miller, 1986; Ernst, 1990) and on a collection of metabolic risk factors variously described under the terms 'metabolic syndrome' or 'syndrome X' (Reaven, 1988) or more recently as 'visceral fat syndrome' (Matsuzawa et al. 1993). Other risk factors, such as raised homocysteine levels (Genest et al. 1990) and poor antioxidant status (Duthie et al. 1993), have excited a great deal of interest because they have implications for our understanding of the mechanisms by which diet influences this disease.

One of the few prospective studies of CHD to have included mortality data for women as well as men was the Renfrew and Paisley study, which carried out a 15-year follow-up of 15339 adults, including 8262 women, in a region of Scotland with very high mortality rates for CHD (Isles et al. 1992). This study, which evaluated only the major risk factors, 


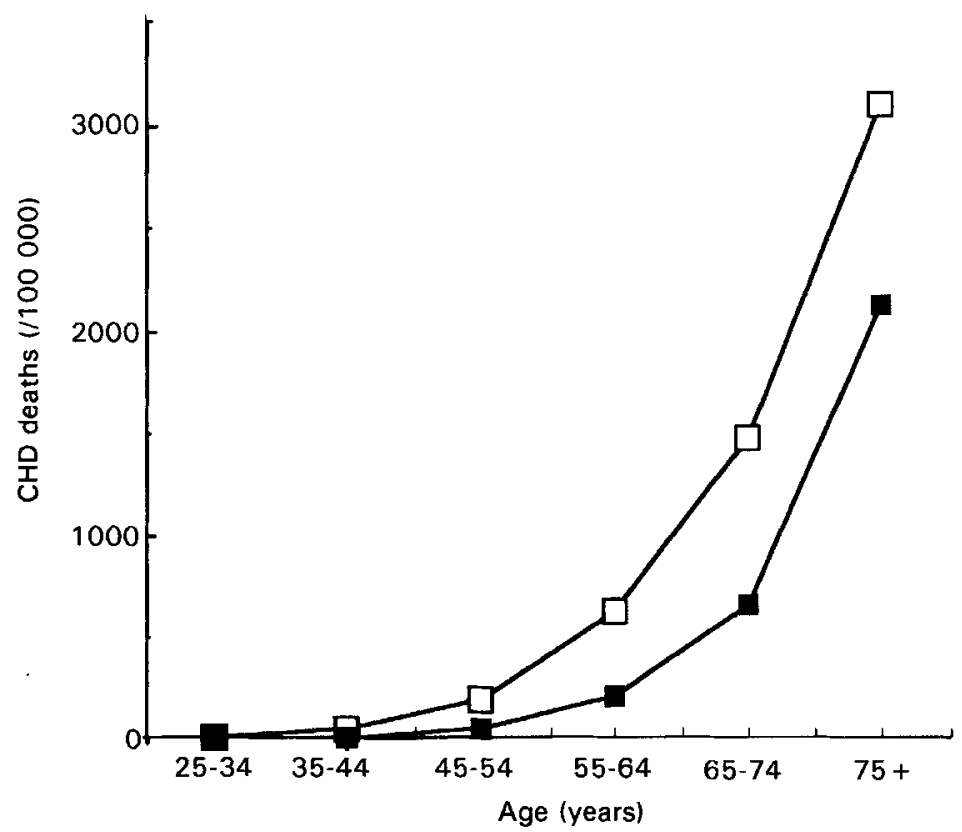

Fig. 1. Annual death rates from coronary heart disease in men ( $\square$ ) and women $(\square)$ in the UK; effects of age. (From World Health Organization, 1989.)

Table 1. Established and proposed risk factors for cardiovascular disease in men and women

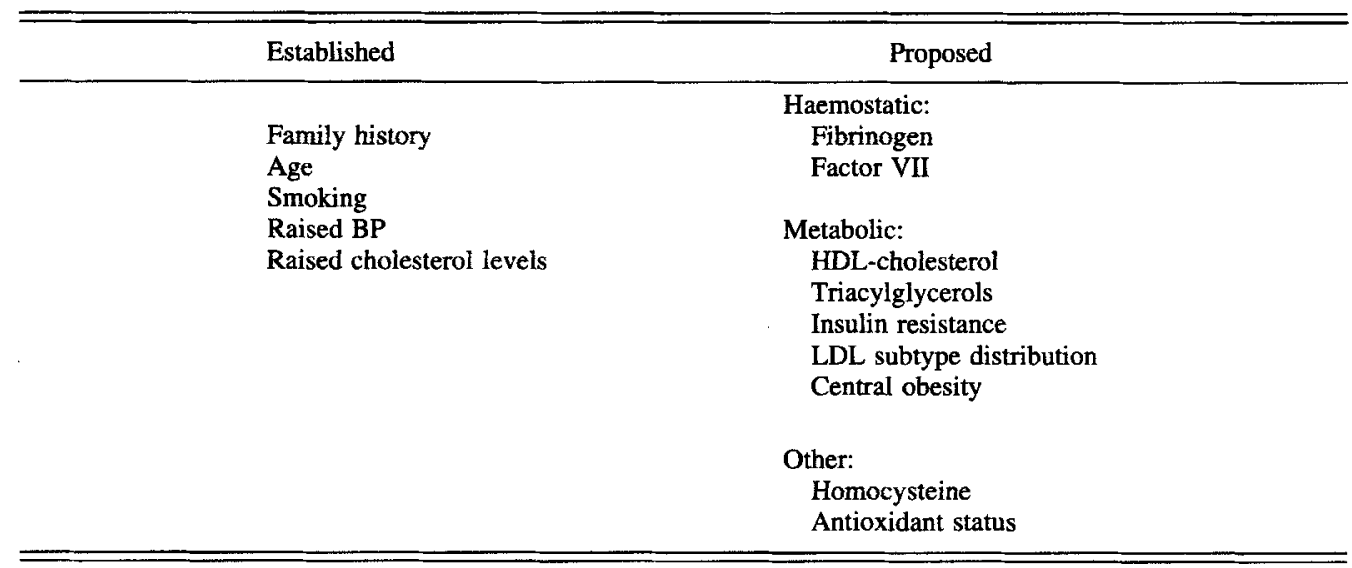

$\mathrm{BP}$, blood pressure.

showed relative risks for blood pressure, cholesterol and smoking to be similar in men and women. However, the study also clearly showed that for varying levels of exposure of each of the risk factors, women had markedly lower rates of CHD mortality than men. The findings for blood cholesterol are of particluar interest (Fig. 2), because in this population the mean cholesterol concentration for women was higher than that for the men, a finding which is consistent with data for the UK adult population in general (Gregory et al. 1990). 


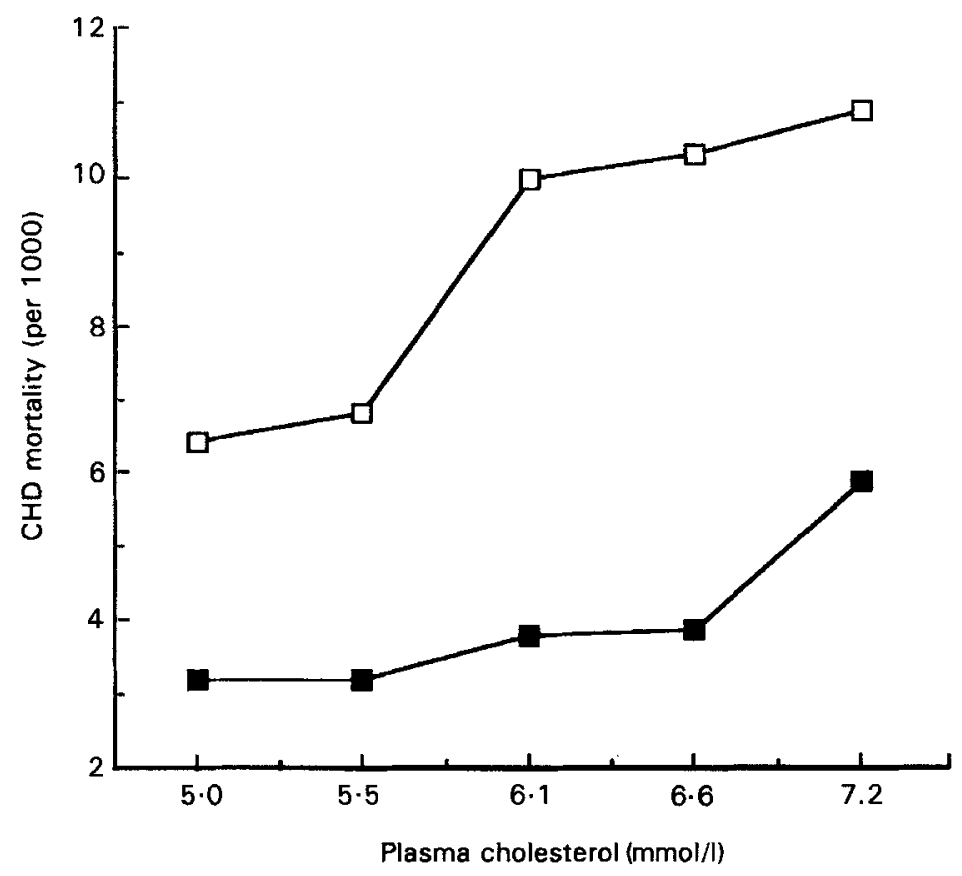

Fig. 2. Adjusted CHD mortality in deaths per 1000 patient years for men ( $\square$ ) and women ( $\square$ ) by quintile of cholesterol. (Redrawn from Isles et al. 1992.)

The findings from the Renfrew study suggest that women are relatively resistant to the adverse effects of established risk factors, and are consistent with the general observation that, despite greater prevalence of abnormal values for cholesterol, hypertension and obesity in women, attributable risks are far lower in the female than the male UK population.

\section{METABOLIC RISK FACTORS}

Evidence has begun to emerge which suggests that the lesser susceptibility of women to CHD may lie partly, but not exclusively, in their lower prevalence of metabolic risk factors (Table 1). In addition, studies conducted over the past 5 years have provided a clearer picture of the mechanism(s) by which insulin resistance and central obesity, the key characteristics of the metabolic syndrome, may be linked to the generation of an atherogenic lipid profile (Fig. 3) (Frayn \& Coppack, 1992; Després \& Lamarche, 1993; Frayn, 1993), of which a short summary is provided here. Fat deposited in the abdominal region is more metabolically active than fat deposited subcutaneously (Arner, 1995) and, therefore, it is proposed, releases greater amounts of non-esterified fatty acids directly into the portal vein (Bjorntorp, 1991), with consequent adverse effects on insulin clearance and degradation (Kissebah et al. 1988). This leads to a state of insulin-resistant hyperinsulinaemia with consequent stimulation, rather than the usual inhibition, of VLDL secretion (Howard et al. 1987; Wiggins \& Gibbons, 1992). This adverse effect of increased VLDL output is added to by high circulating levels of chylomicron (CM) triacylglycerol which arises from impaired activity of insulin on adipose-tissue lipoprotein lipase ( $E C$ 


\section{Mechanism linking effects of metabolic risk factors to atherosclerosis?}

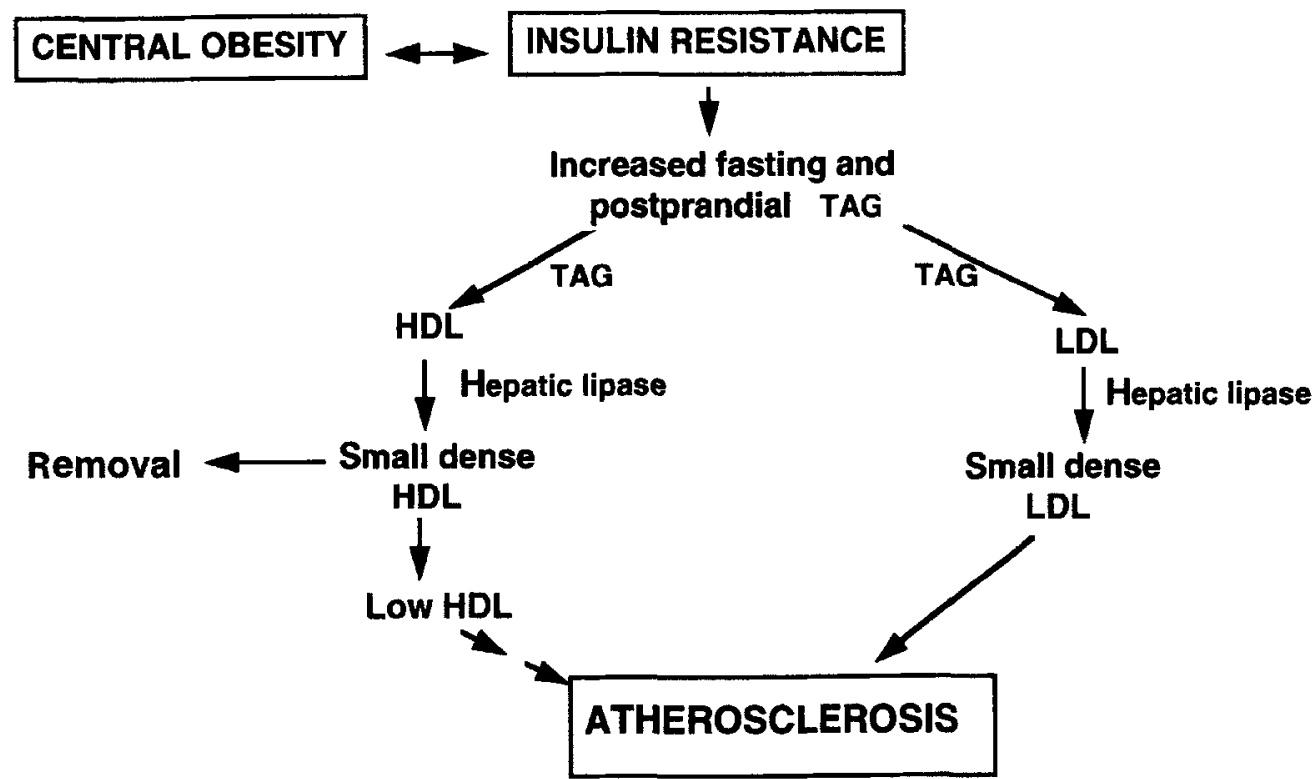

Fig. 3. Outline of proposed mechanism by which insulin resistance and central obesity may be linked to atherogenesis. $T A G$, triacylglycerols; lipase, EC 3.1.1.3.

3.1.1.34; Eckel, 1989; Jeppesen et al. 1995), and these increases in CM and VLDL particles are reflected in both elevated fasting and postprandial triacylglycerol concentrations. The presence of large numbers of triacylglycerol-containing particles results in neutral lipid exchange with transfer of triacylglycerol from CM and VLDL onto HDL and LDL and reciprocal transfer of cholesterol from HDL and LDL onto CM and VLDL (Deckelbaum et al. 1984; Hopkins \& Barter, 1986). The subsequent action of hepatic lipase (EC 3.1.1.3) on triacylglycerol-rich HDL and LDL results in the formation of small dense HDL and LDL particles (Watson et al. 1994). A higher fractional catabolic rate of small dense HDL (Brinton et al. 1994) will result in lower HDL concentrations, a lipid profile consistently linked with increased risk of CHD. Of more recent origin are data which demonstrate a positive relationship between a preponderance of small dense LDL and increased risk of MI (Austin et al. 1988; Griffin et al. 1994). Thus, low HDL and increased prevalence of small dense LDL are suggested to be the atherogenic consequences of insulin resistance and central obesity (Reaven et al. 1993; Selby et al. 1993) arising from adverse effects of the latter on pathways of triacylglycerol metabolism.

\section{SERUM LIPID PROFILES AND BODY FAT DISTRIBUTION IN WOMEN}

The most notable distinguishing feature of the female lipid profile is the higher concentration of HDL-cholesterol (Fig. 4; Gregory et al. 1990) which almost certainly provides significant protection against premature CHD. Although LDL-cholesterol 


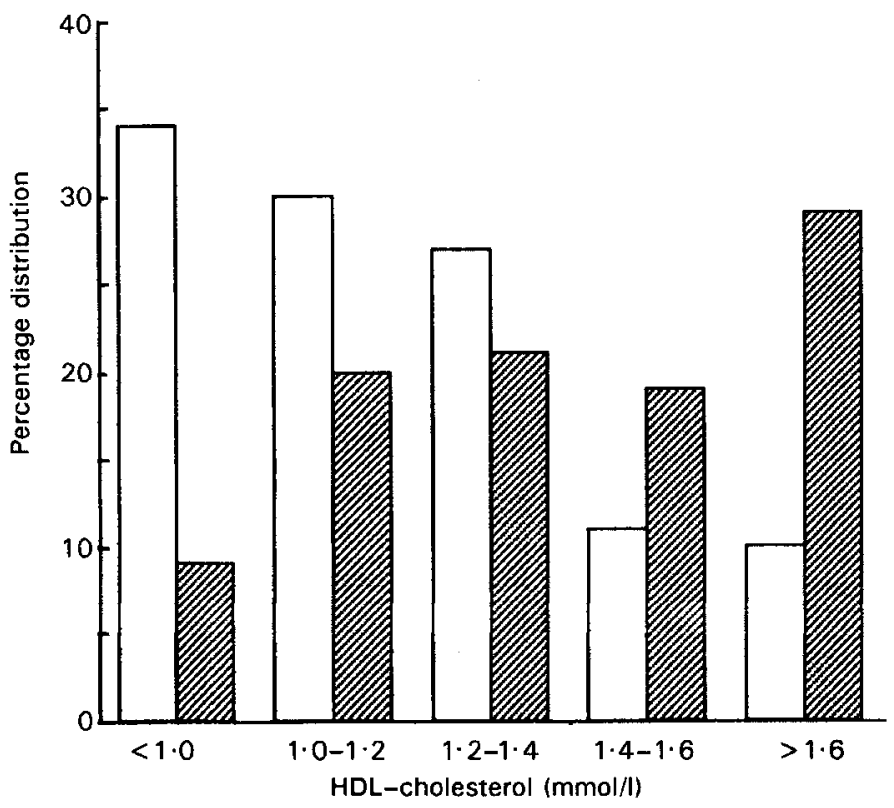

Fig. 4. Percentage distribution of HDL-cholesterol by sex. ( $\square$ ) Men; (甘), women. (Redrawn from Gregory et al. 1990.)

concentrations increase following the menopause, adverse reductions in $\mathrm{HDL}$ are not so marked (Stevenson et al. 1993), and may help to explain why protective effects of female hormones extend for some period of time beyond the menopause. Lower fasting and postprandial concentrations of triacylglycerol are another notable feature of the female lipid profile, which through attenuation of the mechanism described previously may also offer significant protection against $\mathrm{CHD}$. Young female subjects have triacylglycerol concentrations approximately $40 \%$ lower than their male counterparts and although triacylglycerol concentrations increase after the post-menopause, they do not reach levels found in older males and are generally close to values seen in young normolipidaemic males (Cohn et al. 1988). The ability to quantify LDL subtypes separated by their different densities has allowed comparisons of LDL subtype distributions (LDL I, LDL II and LDL III) in male and female populations. In young normo-lipidaemic subjects with normal body weight, there is a clear gender difference in LDL sub-type distribution, with females possessing more of the large buoyant LDL subtype (LDL I) and males more of the small dense LDL subtype (LDL III; Griffin et al. 1990; Tan et al. 1995), the reputedly atherogenic sub-type profile (Austin et al. 1990). Women and men are clearly distinguished by their different fat distributions, with greater preponderance of body fat located around the gluteal regions and less deposited centrally in women compared with men. With age there is a greater tendency for women to develop an androgenic fat distribution, although there remain clear distinctions between men and women (Ley et al. 1992). The recent demonstration by Cefalu et al. (1995), that variations in abdominal fat distribution account for $51 \%$ of the variation in insulin sensitivity in a large group of normal men and women provides support for the view that differences in body fat distribution may be the primary locus through which gender-related differences in CHD risk operate. However, beneficial effects of oestrogen on specific pathways of lipoprotein metabolism almost certainly add to 
this protective effect of body fat distribution. These effects include: up-regulation of the LDL receptor and inhibition of hepatic lipase (McNamara et al. 1987; Tan et al. 1995) and increased synthesis of apoliproprotein A1, the transport protein of HDL.

\section{ABNORMALITIES IN METABOLIC RISK FACTORS IN WOMEN}

The proposal that women have a lesser susceptibility to CHD due to biological protection against development of metabolic risk factors is supported by the observation that when abnormal values of these risk factors are present they greatly reduce differences in CHD risk between men and women. This is clearly seen in women with non-insulin-dependent diabetes mellitus (NIDDM) in whom risk of CHD is increased 4-5-fold, whereas in men, NIDDM increases risk of CHD by only 2-3-fold (Barrett-Connor et al. 1991). Another example is afforded by that of Asian women living in the UK, but born in the Indian subcontinent, who have a very high prevalence of insulin resistance and central obesity and in whom risk of $\mathrm{CHD}$ is rising faster than in the male Asian population (Balarajan, 1991).

Studies of normal non-diabetic female populations also support the proposal that abnormalities in metabolic risk factors are important determinants of CHD in women. A number of studies indicate that these markers may be more important in distinguishing risk of CHD in females than the established risk markers which have been derived from studies of male populations. This is best illustrated by consideration of findings from studies which have evaluated the impact of serum triacylglycerols and central obesity on CHD risk in women. Although fasting triacylglycerols have not been shown to be independent markers of risk for CHD in studies of male populations, at least four prospective studies of female populations have demonstrated elevated fasting triacylglycerol values to be strongly associated with CHD risk (Kannel et al. 1971; Bottinger \& Carlson, 1982; Johanssen et al. 1988; Bengtsson et al. 1993). The Framingham study showed that in women the strongest predictors of $\mathrm{CHD}$ risk were a triacylglycerol value greater than $1.7 \mathrm{mmol} / \mathrm{l}$ and $\mathrm{HDL}$ value less than $1.3 \mathrm{mmol} / 1$ (Castelli et al. 1986; Castelli, 1988). A prospective follow-up of 1462 women over a 20-year period in Gothenburg, Sweden (Bengtsson et al. 1993), demonstrated a strong association between serum triacylglycerol concentrations and CHD mortality. Although total blood cholesterol and BMI were initially shown to be significantly associated with CHD in this population, correction for effects of elevated triacylglycerol in the former and central obesity (waist: hip ratio; WHR) in the latter, removed any significant effects of these two variables. A number of studies have shown central obesity to be a strong risk factor both in men and women, although studies in women (Lapidus et al. 1984; Higgins et al. 1988; Bengtsson et al. 1993; Manson et al. 1995) generally produce values for relative risks which are higher than those found in men (Larsson et al. 1984; Ducimetiere et al. 1986; Donahue et al. 1987). One of the most recently reported studies of anthropometric variables and risk of CHD in women was the 18-year follow-up of the Nurses Health Study (Manson et al. 1995). This study showed BMI, WHR and weight gain in adult life, to be significant risk factors in CHD. Although WHR was not as strong a predictor of total mortality as BMI, the WHR was a very strong preditor of death due to $\mathrm{CHD}$, suggesting that this marker is a specific and highly discriminating risk factor for this disease. The data from this study are of particular value because effects of smoking were controlled for and subjects who died within the first 4 years of follow-up were excluded from the analysis.

Some evidence which mitigates against insulin resistance as a particularly important risk factor for $\mathrm{CHD}$ in women is suggested by two studies which have shown no relationship between insulin sensitivity and CHD in women, but increased risk with 
decreased sensitivity in men (Cullen et al. 1983; Modan et al. 1991). Questions regarding the central role of elevated triacylglycerols and the LDL III subtype as important risk factors in female CHD are also raised by the observation that hormone-replacement therapy, which is now generally accepted as having protective effects against CHD, results in significant increases in fasting triacylglycerol concentrations (Writing Group for the PEPI Trial, 1995) and in an alteration of the LDL subtype pattern towards the more atherogenic form (Griffin et al. 1993). These somewhat paradoxical findings may be explained by the possibility that the most important consideration is the prevailing concentration of HDL. When HDL levels are high, other risk factors become quantitatively less important; since HDL is consistently raised by HRT this may offer some explanation for these observations (Seed \& Crook, 1994).

\section{CONCLUSION}

Women have a lower risk of CHD despite higher prevalence of established risk factors, particularly blood cholesterol and obesity. This may be due to their lower susceptibility to the 'metabolic syndrome' arising from the female pattern of body fat distribution, although this effect is almost certainly added to by the protective effects of oestrogen on specific pathways of lipoprotein metabolism. Raised serum triacylglycerols, lowered HDL and central obesity have emerged as strong discriminators of CHD risk in women and may be more valuable in identifying high-risk female groups than some of the established risk factors. Interventions based around these risk factors, i.e. mechanisms for reducing raised fasting and postprandial triacylglycerols and for preventing weight gain in middle life, may be more appropriate than those which have been used hitherto.

\section{REFERENCES}

Arner, P. (1995). Differences in lipolysis between human subcutaneous and omental adipose tissues. Annals of Medicine 27, 435-438.

Austin, M. A., Breslow, J. I., Hennekens, C. H., Buring, J. E., Willett, W. C. \& Krauss, R. M. (1988). Low density lipoprotein subclass patterns and risk of myocardial infarction. Journal of the American Medical Association 260, 1917-1921.

Austin, M. A., King, M. C., Vrazinana, K. M. \& Krauss, R. M. (1990). Atherogenic lipoprotein phenotype: a proposed genetic marker for coronary heart disease. Circulation 82, 495-506.

Balarajan, R. (1991). Ethnic differences in mortality from ischaemic heart disease and cerebrovascular disease in England and Wales. British Medical Journal 302, 560-564.

Barrett-Connor, E. \& Bush, T. I. (1991). Why is diabetes a stronger risk factor for fatal ischaemic heart disease in women? Journal of the American Medical Association 265, 627-631.

Bengtsson, C., Björkelund, C., Lapidus, L. \& Lissner, L. (1993). Associations of serum lipid concentrations and obesity with mortality in women: 20 year follow up of participants in prospective population study in Gothenburg, Sweden. British Medical Journal 307, 1385-1388.

Bjorntorp, P. (1991). Metabolic implications of body fat distribution. Diabetes Care 14, 1132-1143.

Bottinger, L. E. \& Carlson, L. A. (1982). Risk factors for death for males and females. A study of the death pattern in the Stockholm Prospective Study. Acta Medica Scandinavica 211, 437-442.

Brinton, E. A., Eisenberg, S. \& Breslow, J. L. (1994). Human HDL cholesterol levels are determined by apo A-1 fractional catabolic rate which correlates inversely with estimates of HDL particle size. Effects of gender, hepatic and lipoprotein lipases, triglyceride and insulin levels, and body fat distribution. Arteriosclerosis and Thrombosis 14, 707-720.

Castelli, W. P., Garison, R. J., Wilson, P. W., Abbot, R. D., Kalousdian, S. \& Kannel, W. B. (1986). Incidence of coronary heart disease and lipoprotein cholesterol levels: the Framingham study. Journal of the American Medical Association 256, 2835-2838.

Castelli, W. P. (1988). The triglyceride issue: a view from Framingham. American Heart Joumal 112, $432-437$.

Cefalu, W. T., Wang, Z. Q., Werbel, S., Bell-Farrow, A., Crouse, J. R., Hinson, W. H., Terry, J. G. \& Anderson, R. (1995). Contribution of visceral fat mass to the insulin resistance of aging. Metabolism 44, 954-959. 
Cohn, J. S., McNamara, J. R., Cohn, S. D., Ordovas, J. M. \& Schaefer, E. J. (1988). Postprandial plasma lipoprotein changes in human subjects of different ages. Joumal of Lipid Research 29, 469-479.

Cullen, K., Stenhouse, N. S., Wearne, K. L. \& Welborn, T. A. (1983). Multiple regression analysis of risk factors for cardiovascular disease and cancer mortality in Busselton, Australia - 13 year study. Journal of Chronic Diseases 36, 371-377.

Deckelbaum, R. J., Grannot, E., Oschry, Y., Rose, L. \& Eisenberg, S. (1984). Plasma triglyceride determines structure composition in low and high density lipoproteins. Arteriosclerosis and Thrombosis 4, 225-231.

Després, J.-P. \& Lamarche, B. (1993). Effects of diet and physical activity on adiposity and body fat distribution: Implications for the prevention of cardiovascular disease. Nutrition Research Reviews 6, 137 159.

Donahue, R. P., Abbot, R., Bloom, E., Reed, D. M. \& Katsuhiko-Yano, K. L. (1987). Central obesity and coronary heart disease in men. Lancet 1, 821-824.

Ducimetiere, P., Richard, J. \& Cambien, F. (1986). The pattern of subcutaneous fat distribution in middle aged men and the risk of coronary heart disease. The Paris Prospective Study. International Journal of Obesity 10, 229-240.

Duthie, G. G., Arthur, J. R., Beattie, J. A., Brown, K. M., Morrice, P. C., Robertson, J. D., Shortt, C. T., Walker, K. A. \& James, W. P. T. (1993). Cigarette smoking, antioxidants, lipid peroxidation and coronary heart disease. Annals of the New York Academy of Sciences 686, 120-129.

Eckel, R. H. (1989). Lipoprotein lipase. A multifunctional enzyme relevant to common metabolic diseases. New England Journal of Medicine 320, 1060-1068.

Ernst, E. (1990). Plasma fibrinogen - an independent cardiovascular risk factor. Journal of Internal Medicine 227, 365-372.

Frayn, K. N. (1993). Insulin resistance and lipid metabolism. Current Opinions in Lipidology 4, 197-204.

Frayn, K. N. \& Coppack, S. W. (1992). Insulin resistance, adipose tissue and coronary heart disease. Clinical Science 82, 1-8.

Genest, J. J., McNamara, J. R., Salen, D. N., Wilson, P. W., Schaefer, E. J. \& Malinow, M. R. (1990). Plasma homocysteine levels in men with premature coronary artery disease. Journal of the American College of Cardiology 16, 1104-1111.

Gregory, J., Foster, K., Tyler, H. \& Wiseman, M. (1990). The Dietary and Nutritional Survey of British Adults. London: H. M. Stationery Office.

Griffin, B., Farish, E., Walsh, D., Barnes, J., Caslake, M., Shepherd, J. \& Hart, D. (1993). Response of plasma low density lipoprotein subfractions to oestrogen replacement therapy following surgical menopause. Clinical Endocrinology 39, 463-468.

Griffin, B. A., Caslake, M. J., Yip, B., Tait, G. W., Packard, C. J. \& Shepherd, J. (1990). Rapid isolation of low density lipoprotein (LDL) subfractions from plasma by density gradient ultracentrifugation. Atherosclerosis 83, 59-67.

Griffin, B. A., Freeman, D. J., Tait, G. W., Thomson, J., Caslake, M. J., Packard, C. J. \& Shepherd, J. (1994). Role of plasma triglyceride in the regulation of plasma low density lipoprotein (LDL) subfractions: relative contribution of small dense LDL to coronary heart disease. Atherosclerosis 106, 241-253.

Higgins, M., Kannel, W. M., Garrison, R., Pinsky, J. \& Stokes, J. (1988). Hazards of obesity - The Framingham Experience. Acta Medica Scandinavica 723, 23-36.

Hopkins, G. J. \& Barter, P. J. (1986). Role of triglyceride-rich lipoproteins and hepatic lipase in determining the particle size of and composition of high density lipoprotein. Journal of Lipid Research 27, 1265-1277.

Howard, B. V., Abbott, W. G. H., Egussa, G. \& Taskinen, M.-R. (1987). Coordination of very low density lipoprotein triglyceride and apolipoprotein B metabolism in humans: effects of obesity and non-insulin dependent diabetes mellitus. American Heart Journal 113, 522-526.

Hulley, S. B., Walsh, J. M. \& Newman, T. B. (1992). Health policy on blood cholesterol: time to change directions. Circulation 86, 1026-1029.

Isles, C. G., Hole, D. J., Hawthorne, V. M. \& Lever, A. F. (1992). Relation between coronary risk and coronary mortality in women of the Renfrew and Paisley survey: comparison with men. Lancet 339, 702-706.

Jeppesen, J., Hollenbeck, C. B., Zhou, M.-Y., Coulston, A. M., Jones, C., Chen, Y.-D. I. \& Reaven, G. M. (1995). Relation between insulin resistance, hyperinsulinemia, postheparin plasma lipoprotein lipase activity, and postprandial lipemia. Arteriosclerasis, Thrombosis and Vascular Biology 15, 320-324.

Johanssen, S., Bondjets, G., Fager, G., Wedel, H., Espogramn, A. \& Olotsson, S. O. (1988). Serum lipids and apolipoprotein levels in women with acute myocardial infarction. Arteriosclerosis 8, 742-749.

Kannel, W. B., Castelli, W. B., Gordon, I. \& McNamara, P. M. (1971). Serum cholesterol lipoproteins and the risk of coronary heart disease. The Framingham Study. Annals of Internal Medicine 74, 1-12.

Kannel, W. B., Sorlie, P. \& McNamara, P. M. (1979). Prognosis after myocardial infarction; the Framingham Study. American Journal of Cardiology 44, 53-59.

Kissebah, A. H., Peiris, A. N. \& Evans, D. J. (1988). Mechanisms associating body fat distribution to glucose intolerance and diabetes mellitus; Window with a view. Acta Medica Scandinavica 723, 79-89. 
Lapidus, L., Bengtsson, C., Larsson, B., Pennert, K., Rybo, E. \& Sjostrom, L. (1984). Distribution of adipose tissue and risk of cardiovascular disease and death: a 12 year follow up of participants in the population study of women in Gothenburg, Sweden. British Medical Journal 289, 1257-1261.

Larsson, B., Svardsudd, K., Welin, L., Wilhelmsen, L., Bjorntorp, P. \& Tibblin, G. (1984). Abdominal adipose tissue distribution, obesity and risk of cardiovascular disease and death: 13 year follow up of the participants in the study of men born in 1913. British Medical Journal 288, 1401-1404.

Ley, C. J., Lees, B. \& Stevenson, J. C. (1992). Sex- and menopause-associated changes in body-fat distribution. American Journal of Clinical Nutrition 55, 950-954.

McNamara, J. R., Campos, H., Ordovas, J., Peterson, P. W. F. \& Schaefer, E. F. (1987). Effect of gender, age and lipid status on low density lipoprotein subfraction distribution. Results from the Framingham Offspring Study. Arteriosclerosis 7, 483-490.

Manson, J. E., Willett, W. C., Stampfer, M. J., Colditz, G. A., Hunter, D. J., Hankinson, S. E., Hennekens, C. H. \& Speizer, F. E. (1995). Body weight and mortality among women. New England Journal of Medicine 333, $677-685$.

Matsuzawa, Y., Shimomura, I. \& Nakamura, T. (1993). Pathophysiology and pathogenesis of visceral fat obesity. Annals of the New York Academy of Sciences 676, 270-278.

Meade, T. W., Ruddock V., Stirling, Y., Chakrabarti, R. \& Miller, G. J. (1986). Fibrinolytic activity, clotting factors and long term incidence of ischaemic heart disease in the Northwick Park Heart Study. Lancet 342 , 1076-1079.

Miller, G. J. (1986). Association between dietary fat intake and plasma factor VII coagulant activity - a predictor of cardiovascular mortality. Atherosclerosis 60, 269-277.

Modan, M., Or, J. \& Karasik, A. (1991). Hyperinsulinemia, sex, and risk of atherosclerotic cardiovascular disease. Circulation 84, 1165-1175.

Office of Population Censuses and Surveys (1993). Deaths From Coronary Heart Disease/100,000 for Males and Females Aged 35-44, 45-54 and 55-64 in England and Wales, in Scotland and in Northerm Ireland in the Years 1950-51 to 1986-87. London: H. M. Stationery Office.

Reaven, G. M. (1988). Role of insulin resistance in human disease. Diabetes 37, 1595-1607.

Reaven, G. M., Chen, Y. D. I., Jeppesen, J., Maheux, P. \& Krauss, R. M. (1993). Insulin resistance and hyperinsulinemia in individuals with small dense low density lipoprotein particles. Journal of Clinical Investigation 92, 141-146.

Seed, M. \& Crook, D. (1994). Post-menopausal hormone replacement therapy, coronary heart disease and plasma lipoproteins. Current Opinion in Lipidology 5, 48-58.

Selby, J. V., Austin, M. A., Newman, B., Zhang, D., Quesenberry, C. P., Mayer, E. J. \& Krauss, R. M. (1993). LDL subclass phenotypes and the insulin resistance syndrome in women. Circulation 88, 381-387.

Stevenson, J. C., Crook, D. \& Godsland, I. F. (1993). Effects of age and menopause on lipid metabolism in healthy women. Arteriosclerosis $98,83-90$.

Tan, C. E., Forster, L., Caslake, M. J., Bedford, D., Watson, T. D. G., McConnell, M., Packard, C. J. \& Shepherd, J. (1995). Relations between plasma lipids and postheparin plasma lipases and VLDL and LDL subfraction patterns in normolipemic men and women. Arteriosclerosis, Thrombosis and Vascular Biology 15, 1939-1948.

Walsh, J. M. E. \& Grady, D. (1995). Treatment of hyperlipidemia in women. Journal of the American Medical Association 274, 1152-1158.

Watson, T. D. G., Caslake, M. J., Freeman, D. J., Griffin, B. A., Hinnie, J., Packard, C. J. \& Shepherd, J. (1994). Determinants of LDL subfraction distribution and concentrations in young normolipidemic subjects. Arteriosclerosis and Thrombosis 14, 902-910.

Wiggins, D. \& Gibbons, G. F. (1992). The lipolysis/esterification cycle of hepatic triacylglycerol. Its role in the secretion of very low density lipoprotein and its response to hormones and sulphonylureas. Biochemical Journal 284, 457-462.

World Health Organization (1989). The WHO MONICA Project: a world wide monitoring system for cardiovascular diseases. World Health Statistics Annual, 1989. Geneva: WHO.

Writing Group for the PEPI Trial (1995). Effects of estrogen or estrogen/progestin regimens on heart disease risk factors in postmenopausal women. The Postmenopausal Estrogen/Progestin Interventions (PEPI) Trial. Journal of the American Medical Association 273, 199-208. 